\title{
Article
}

\section{A novel multiplex assay for simultaneously analysing 13 rapidly mutating Y-STRs}

Alghafri, Rashed Hamdan Nasser h-binamma, Goodwin, William H, Ralf, Arwin, Kayser, Manfred and Hadi, Ss

Available at http://clok.uclan.ac.uk/13861/

Alghafri, Rashed Hamdan Nasser h-binamma, Goodwin, William H ORCID: 0000-0002-3632-3552, Ralf, Arwin, Kayser, Manfred and Hadi, Ss ORCID: 0000-0002-2994-3083 (2015) A novel multiplex assay for simultaneously analysing 13 rapidly mutating Y-STRs. Forensic Science International:

Genetics, 17 . pp. 91-98. ISSN 1872-4973

It is advisable to refer to the publisher's version if you intend to cite from the work. http://dx.doi.org/10.1016/j.fsigen.2015.04.004

For more information about UCLan's research in this area go to http://www.uclan.ac.uk/researchgroups/ and search for <name of research Group>.

For information about Research generally at UCLan please go to http://www.uclan.ac.uk/research/

All outputs in CLoK are protected by Intellectual Property Rights law, including Copyright law. Copyright, IPR and Moral Rights for the works on this site are retained by the individual authors and/or other copyright owners. Terms and conditions for use of this material are defined in the policies page.

\section{CLoK}

Central Lancashire online Knowledge www.clok.uclan.ac.uk

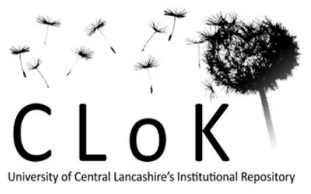




\title{
elsevier_FSIGEN_1339
}

Short Eূcommunication

Single A novel multiplex assay for simultaneously analysing 13 Rapidly Mrapidly mutating Y-STRs

Rashed Alghafria, b

Will Goodwin ${ }^{\mathrm{a}}$

Arwin Ralf ${ }^{\mathrm{C}}$

Mantred Kayser

Sibte Hadia, *

shadi@uclan.ac.uk

aUniversity of Central Lancashire, School of Forensic and Investigative Sciences, Preston, UK

${ }^{\mathrm{b} G e n e r a l ~ D e p a r t m e n t ~ o f ~ F o r e n s i c ~ S c i e n c e s ~ a n d ~ C r i m i n o l o g y, ~ D u b a i ~ P o l i c e ~ G e n e r a l ~ H e a d ~ Q u a r t e r s, ~ D u b a i, ~ U n i t e d ~ A r a b ~ E m i r a t e s ~}$

'Department of Forensic Molecular Biology, Erasmus MC University Medical Centre Rotterdam, Rotterdam, The Netherlands

${ }^{*}$ Corresponding author at: School of Forensic and Investigative Sciences, University of Central Lancashire, JB Firth Building, Preston, PR1 2HE, United Kingdom. Tel.: +44 1772 894395 ; fax: +44 1772894981.

\begin{abstract}

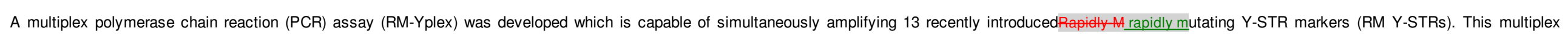

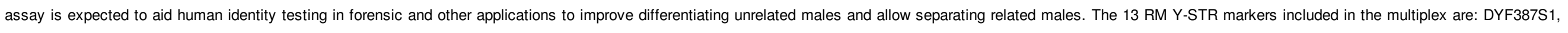

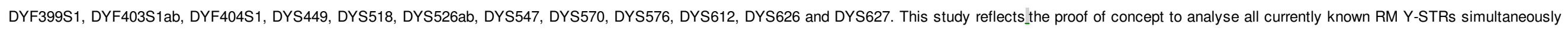

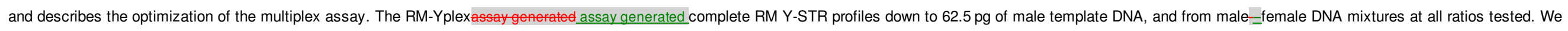
herewith introduce and make available for widespread use in forensic and anthropological studies, an effective and sensitive single multiplex assay for simultaneous genotyping of 13 RM Y-STRs.
\end{abstract}

Keywords: Y-chromosomal STRs; Y-STRs; Rapidly Amutating Y-STRs; Haplotypes

\section{Introduction}

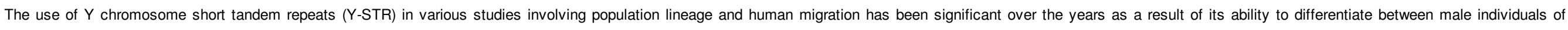

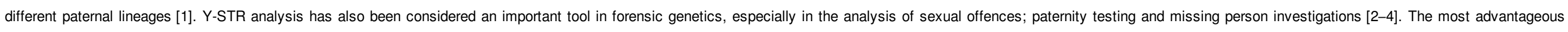

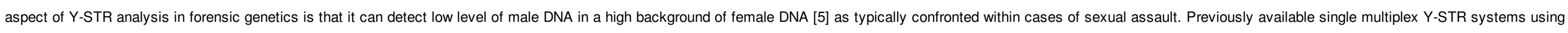

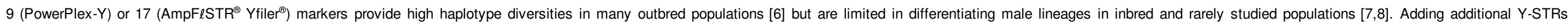

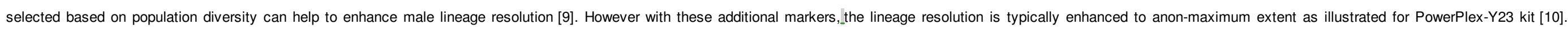

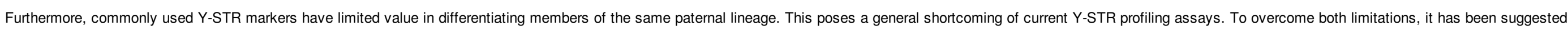
to use Y-STRs with higher mutation rates [11].

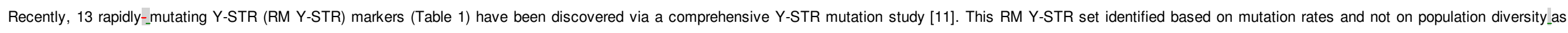

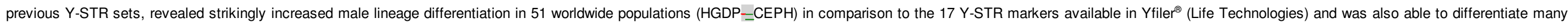

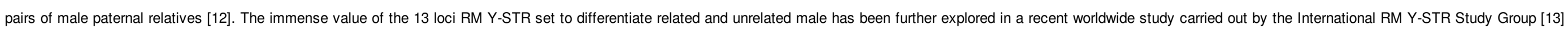




\section{elsevier_FSIGEN_1339}

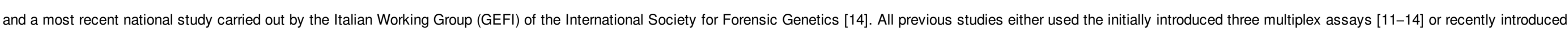
two multiplex assays [15] for amplifying the_13 RM Y-STR markers. In the present study, we developed and optimised the single RM-Yplex assay for the simultaneous amplification of all 13 RM Y-STR_markers.

Table 113 RM Y-STR markers, their_repeat motifs, allele ranges and PCR product sizes as used in the single RM-Yplex developed here

\begin{tabular}{|c|c|c|c|c|}
\hline Locus & Repeat type & Repeat motif (variant in bold) & Allele ranges & Product sizes \\
\hline DYF387S1 & Tetra, complex & $(\mathrm{AAAG})_{3}(\mathrm{GTAG})_{1}(\mathrm{GAAG})_{4} \mathrm{~N}_{16}(\mathrm{GAAG})_{9}(\mathrm{AAAG})_{13}$ & $34-42$ & $240-272$ \\
\hline DYF399S1 & Tetra, complex & $(\mathrm{GAAA})_{3} \mathrm{~N}_{7-8}(\mathrm{GAAA})_{10-23}$ & $15-31$ & $264-322$ \\
\hline DYF403S1a & Tetra, complex & $(\mathrm{TTCT})_{10-17} \mathrm{~N}_{2-3}(\mathrm{TTCT})_{3-17}$ & $4-20$ & $298-348$ \\
\hline DYF403S1b & Tetra, complex & $(\mathrm{TTCT})_{12} \mathrm{~N}_{2}(\mathrm{TTCT})_{8}(\mathrm{TTCC})_{9}(\mathrm{TTCT})_{14} \mathrm{~N}_{2}(\mathrm{TTCT})_{3}$ & $42-55$ & $416-468$ \\
\hline DYF404S1 & Tetra, complex & $(\text { TTTC })_{10-20} \mathrm{~N}_{42}(\text { TTTC })_{3}$ & $11-17$ & $174-198$ \\
\hline DYS449 & Tetra, complex & $(\text { TTTC })_{12-18} \mathrm{~N}_{22}(\mathrm{TTTC})_{3} \mathrm{~N}_{12}(\mathrm{TTTC})_{12-18}$ & $25-36$ & $300-344$ \\
\hline DYS518 & Tetra, complex & $(\mathrm{AAAG})_{3}(\mathrm{GAAG})_{1}(\mathrm{AAAG})_{14-22}(\mathrm{GGAG})_{1}(\mathrm{AAAG})_{4} \mathrm{~N}_{6}(\mathrm{AAAG})_{11-19} \mathrm{~N}_{27}(\mathrm{AAGG})_{4}$ & $34-47$ & $258-308$ \\
\hline DYS526a & Tetra, complex & $(\mathbf{C C T T})_{10-17}$ & $11-18$ & $132-160$ \\
\hline DYS526b & Tetra, complex & $(\mathrm{CCCT})_{3} \mathrm{~N}_{20}(\mathrm{CTTT})_{11-17}(\mathrm{CCTT})_{6-10} \mathrm{~N}_{113}(\mathrm{CCTT})_{10-17}$ & $30-42$ & $340-388$ \\
\hline DYS547 & Tetra, complex & $(\mathbf{C C T T})_{9-13} \mathrm{~T}(\mathrm{CTTC})_{4-5} \mathrm{~N}_{56}(\mathrm{TTTC})_{10-22} \mathrm{~N}_{10}(\mathrm{CCTT})_{4}(\mathrm{TCTC})_{1}(\mathrm{TTTC})_{9-16} \mathrm{~N}_{14}(\mathrm{TTTC})_{3}$ & $42-52$ & $408-448$ \\
\hline DYS570 & Tetra, simple & $(\mathrm{TTTC})_{14-24}$ & $14-22$ & $120-152$ \\
\hline DYS576 & Tetra, simple & $(\mathbf{A A A G})_{13-22}$ & $12-22$ & $170-210$ \\
\hline DYS612 & Tri simple & $(\mathrm{CCT})_{5}(\mathrm{CTT})_{1}(\mathrm{TCT})_{4}(\mathrm{CCT})_{1}(\mathrm{TCT})_{19-31}$ & $31-40$ & $185-213$ \\
\hline DYS626 & Tetra, complex & $(\mathrm{GAAA})_{14-23} \mathrm{~N}_{24}(\mathrm{GAAA})_{3} \mathrm{~N}_{6}(\mathrm{GAAA})_{5}(\mathrm{AAA})+(\mathrm{AAA})_{1}(\mathrm{GAAA})_{2-3}(\mathrm{GAAG})_{1}(\mathrm{GAAA})_{3}$ & $24-35$ & $222-266$ \\
\hline DYS627 & Tetra, complex & $(A G A A)_{3} N_{16}(A G A G)_{3}(\text { AAAG })_{12-24} N_{81}(A A G G)_{3}$ & $15-24$ & $308-344$ \\
\hline
\end{tabular}

\section{Materials and methods}

\subsection{Sample collection and extraction}

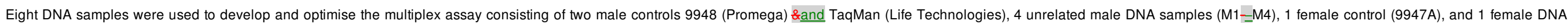

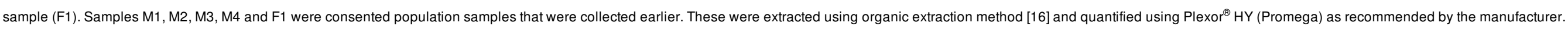

\subsection{Multiplex development and primer design}

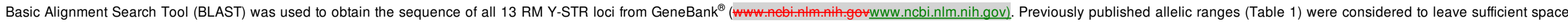

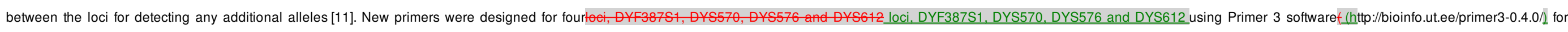
adjusting their positions within the design of this 5-dye RM-Yplex assay (Fig. 1) [17,18]. 


\section{elsevier_FSIGEN_1339}

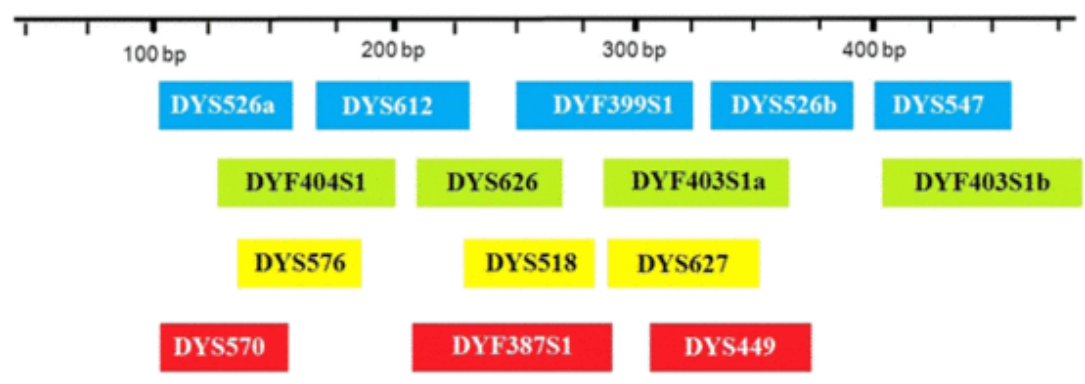

|| || || | | | | || || LIZ600 || || | | || | | |

Fig. 1 Diagram illustrating fluorescent dye label colours used and PCR product size ranges achieved for the 13 RM Y-STR markers incorporated in the single RM-Yplex assay.

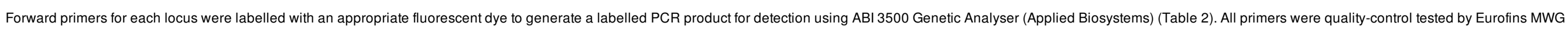
Operon using HPLC method [19]. GeneScan ${ }^{\mathrm{TM}} 600 \mathrm{LIZ}^{\circledR}$ (Life Technologies) was used as an internal standard. G5 matrix (Life Technologies) compatible dye panel was selected for the assay.

Table 2 Primer sequences and concentrations developed and optimised for the RM-Yplex assay. Different flouropores are also indicated.

\begin{tabular}{|c|c|c|c|}
\hline Locus & Primer sequence & Concentration $\mu \mathrm{M}$ & Reference \\
\hline \multirow[t]{2}{*}{ DYF387S1 } & Forward: ATTO565-ATTO565-ACAGAGCTAGATTCCATTTTACCC & 0.05 & Present Ss $\underline{\text { tudy }}$ \\
\hline & Reverse: GCCACAGTGTGAGAAGTGTGA & 0.05 & \\
\hline \multirow[t]{2}{*}{ DYF399S1 } & Forward: 6FAM-6-FAM-GGGTTTTCACCAGTTTGCAT & 0.06 & [11] \\
\hline & Reverse: CCATGTTTTGGGACATTCCT & 0.06 & \\
\hline \multirow[t]{2}{*}{ DYF403S1a/b } & Forward: ¥akimaYellow-YakimaYellow-CAAAATTCATGTGGATAATGAG & 0.40 & [11] \\
\hline & Reverse: ACAGAGCAGGATTCCATCTA & 0.40 & \\
\hline \multirow[t]{2}{*}{ DYF404S1 } & Forward: ҰakimaYellow-YakimaYellow-GGCTTAAGAAATTTCAACGCATA & 0.11 & [11] \\
\hline & Reverse: CCATGATGGAACAATTGCAG & 0.11 & \\
\hline \multirow[t]{2}{*}{ DYS449 } & Forward: ATTO565-ATTO565-TGGAGTCTCTCAAGCCTGTTC & 0.06 & [11] \\
\hline & Reverse: CCATTGCACTCTAGGTTGGAC & 0.06 & \\
\hline \multirow[t]{2}{*}{ DYS518 } & Forward: ATTO550-ATTO550-GGCAACACAAGTGAAACTGC & 0.12 & [11] \\
\hline & Reverse: TCAGCTCTTACCATGGGTGAT & 0.12 & \\
\hline DYS526a/b & $\begin{array}{l}\text { Forward: 6-FAM-6-FAM-TCTGGTGAACTGATCCAAACC } \\
\text { Reverse: GGGTTACTTCGCCAGAAGGT }\end{array}$ & $\begin{array}{l}0.40 \\
0.40\end{array}$ & [11] \\
\hline \multirow[t]{2}{*}{ DYS547 } & Forward: 6-FAM-6-FAM-TCCATGTTACTGCAAAATACAC & 0.40 & [11] \\
\hline & Reverse: TGACAGAGCATAAACGTGTC & 0.40 & \\
\hline \multirow[t]{2}{*}{ DYS570 } & Forward: ATT0565-ATT0565-CTGGCTGTGTCCTCCAAGTT & 0.04 & Present Ss $\underline{\text { tudy }}$ \\
\hline & Reverse: GGCAACCTAAGCTGAAATGC & 0.04 & \\
\hline \multirow[t]{2}{*}{ DYS576 } & Forward: ATTO550-ATTO550-GTTGGGCTGAGGAGTTCAATC & 0.03 & Present Ss study \\
\hline & Reverse: GGCAGTCTCATTTCCTGGAG & 0.03 & \\
\hline
\end{tabular}




\section{elsevier_FSIGEN_1339}

DYS612

\subsection{RM-YplexA assay PCR amplification conditions}

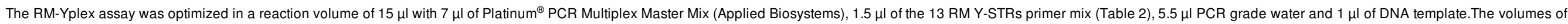

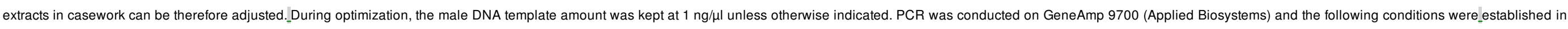
9600 -emulation mode (i.e. ramp speeds of $1^{\circ} \mathrm{C} / \mathrm{s}$ ):

- $95^{\circ} \mathrm{C}$ for 10 minutes.

- 12 cycles: $94^{\circ} \mathrm{C}$ for 30 sonds, $58^{\circ} \mathrm{C}$, $588^{\circ} \mathrm{C}$ for $45,2^{\circ}, 72{ }^{\circ} \mathrm{C}$ for $60 \mathrm{~s}$.

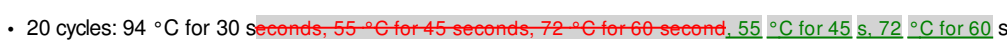

- $72{ }^{\circ} \mathrm{C}$ for 45 minutes:

\subsection{Detection and analysis of PCR products}

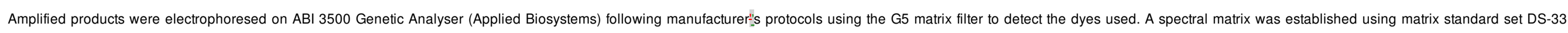

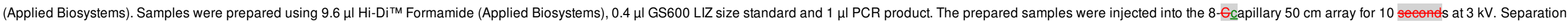

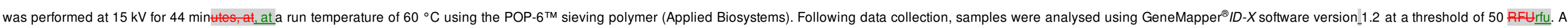

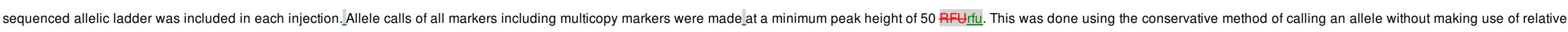
peak height in case of multicopy markers.

\subsection{Multiplex performance studies}

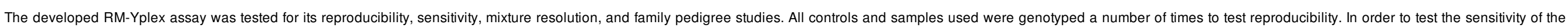

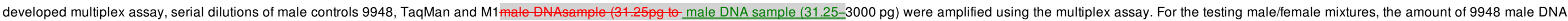

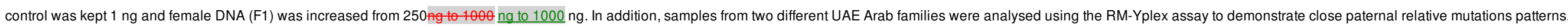

\subsection{Development of allelic ladder}

\subsubsection{Alleles purification}

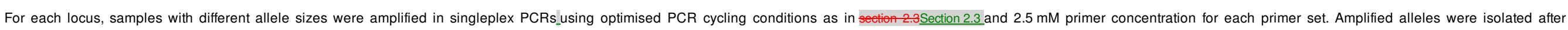

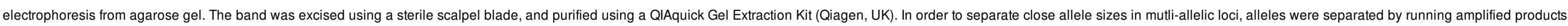
on a polyacrylamide gel before purification.

\subsubsection{Alleles sequencing}

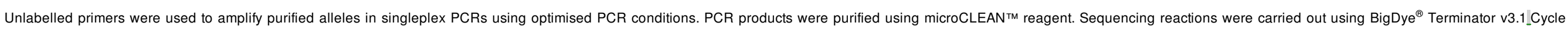




\section{elsevier_FSIGEN_1339}

Sequencing Kit (Applied Biosystems). Each allele was sequenced twice using forward and reverse primers for confirming DNA sequence.

\subsubsection{Allelic ladder construction}

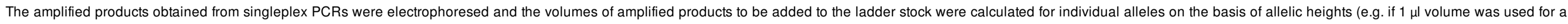

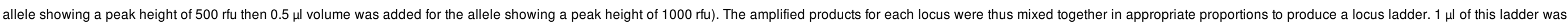

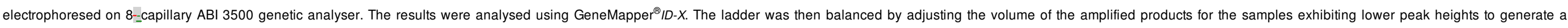

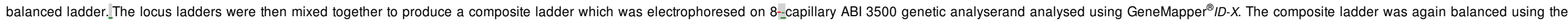
strategy for locus ladders. This produced a stock of balanced composite allelic ladder for further use [20].

The ladder so developed was quality tested using the allelic ladder and quality control DNA samples used by the International RM Y-STR Study Group [13]2.2.

\subsection{Comparability of outcomes and nomenclature}

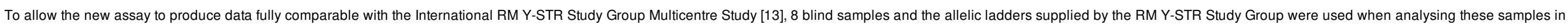
addition to our own allelic ladders. The International RM-YSTR group repeat nomenclature was used for allelic designation. All samples amplified robustly and the results were consistent with those of the International RM-YSTR group.

\section{Results and discussion}

\subsection{RM-Yplex description}

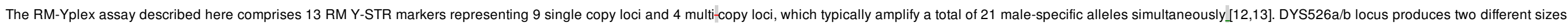

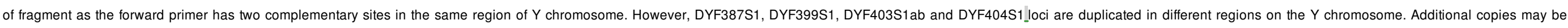
expected as have been identified for the classical Y-STRs with increased population sample sizes (see YHRD for overview).

\subsection{Development and optimisation of RM-Yplex assay}

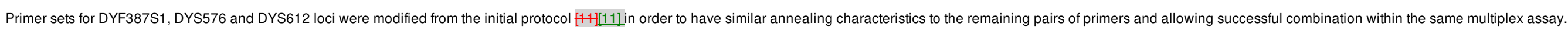

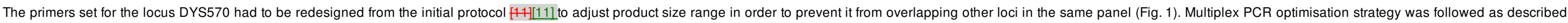
elsewhere [21].A sequenced allelic ladder was developed for the RM-Yplex assay during this work (Fig. 4).

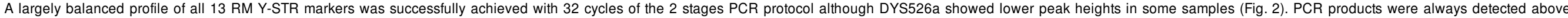

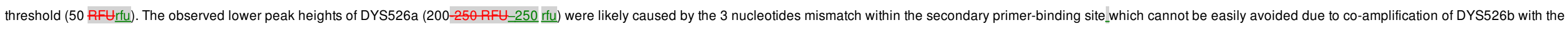
same primer pair. This was confirmed through sequencing (Fig. 3). 


\section{elsevier_FSIGEN_1339}

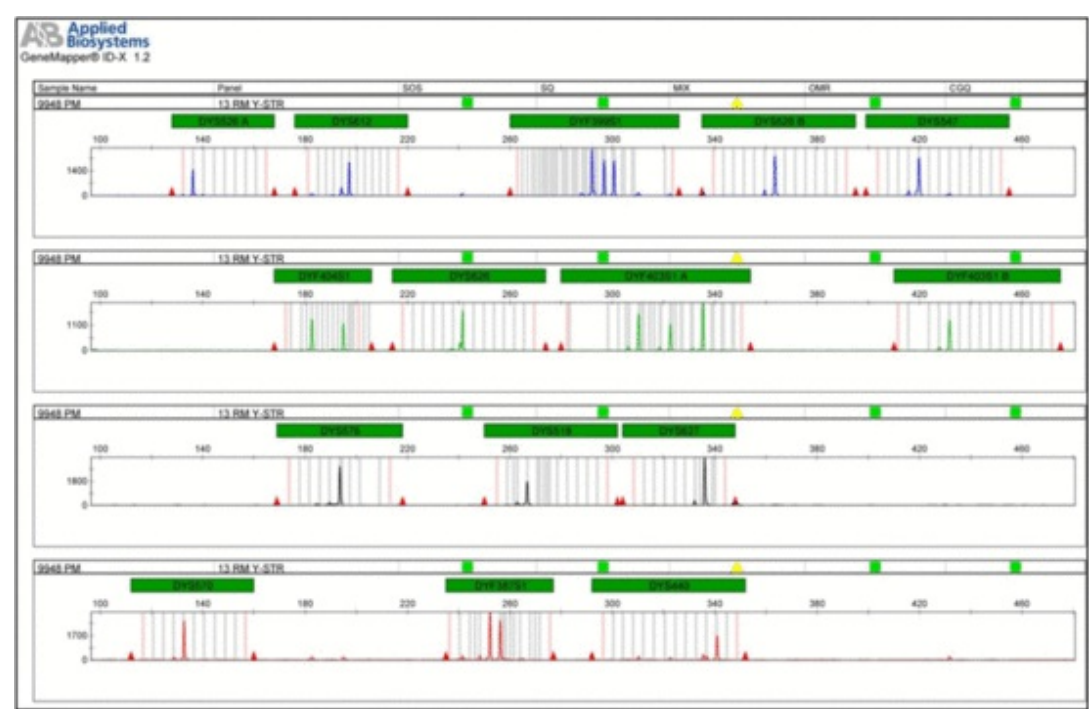

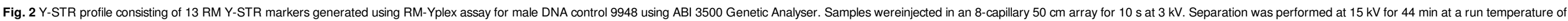
$60{ }^{\circ} \mathrm{C}$ using the POP-6 ${ }^{\mathrm{TM}}$ polymer.

TCTGGTGAACTGATCCAAACCTTTACTTATTTTCTTCСTTTTTССТСТСТССТTСССТC СТССССТTTCTTCCTTTCTTTCTTCCTTTCTTTCTTTCTTTCTTTCTTTCTTTCTTTCTTTCT

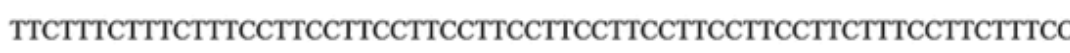
TTCATTTCTTCTTTCTTTCTCTTTACCTTCTGGGAGACTGATCCAAACCTTTACTTACTTT

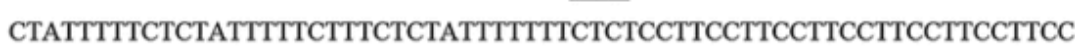
TTCCTTCCTTCCTTCCTTCCTTCCTTCCTTCTCTTTACCTTCTGGCGAAGTAACCC

Fig. 3 Sequencing results of DYS526ab locus illustrating the mismatch (underlined) position at the second attachment site of the forward primer producing the shorter fragment of the locus.

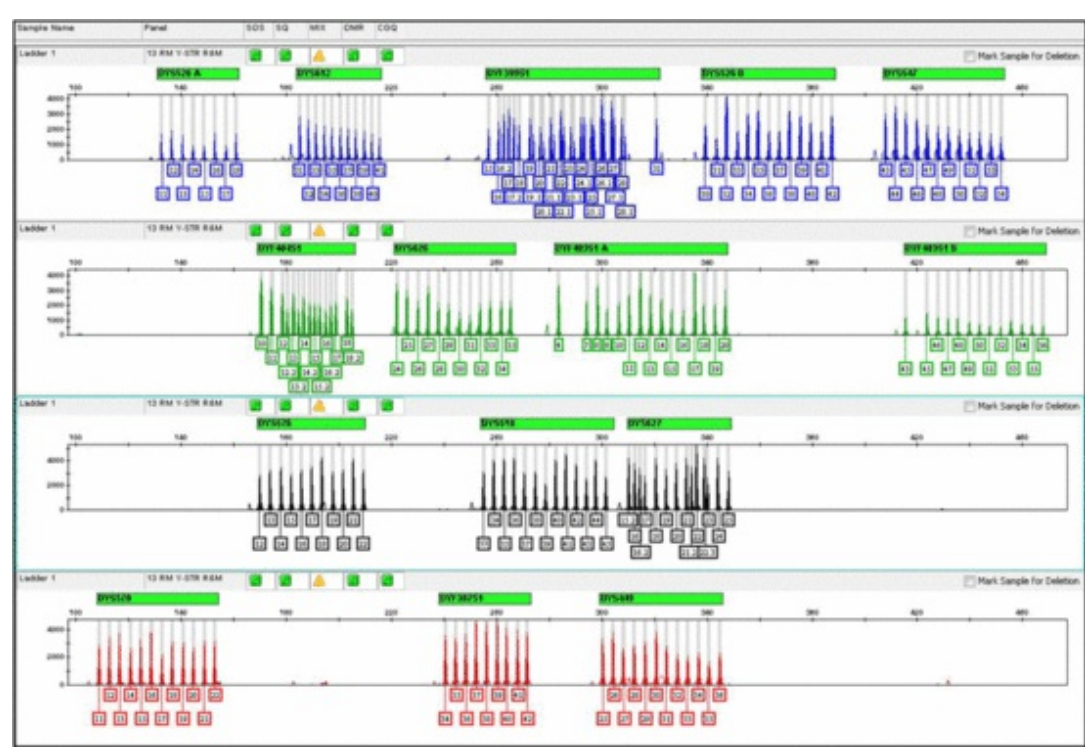




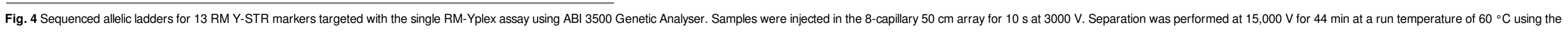
POP-6тм polymer. The allele designation nomenclature was adopted from thelnternational RM Y-STR Study Group's multicentre study [13].

\subsection{Multiplex performance}

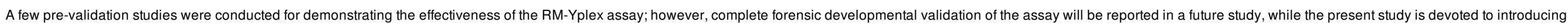

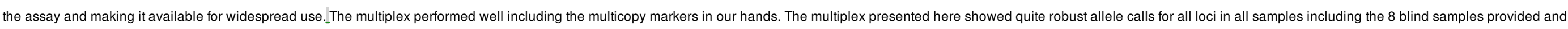

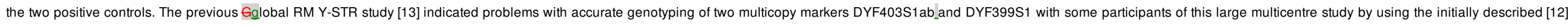

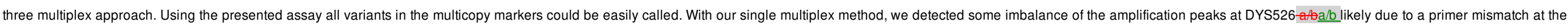

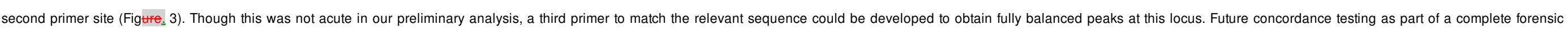
validation study will demonstrate the performance of our multiplex assay in different labs.

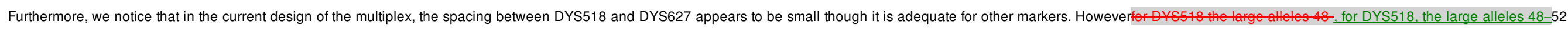

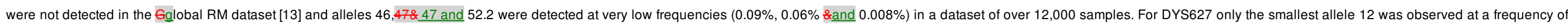
$0.008 \%$ in the same dataset. Thus a possibility of an overlap between these two markers appears to have an extremely low probability. However! the authors are conscious of this and this might need consideration in further works.

\subsubsection{Reproducibility and sensitivity testing}

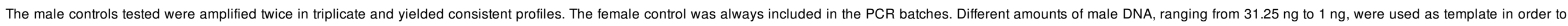

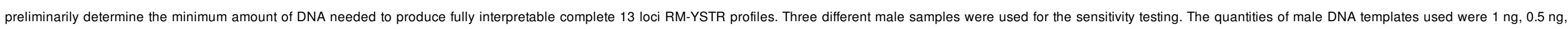

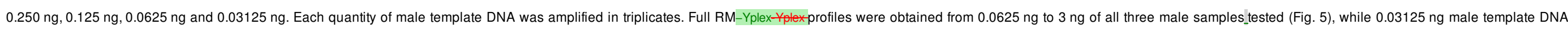
yielded partial profiles. This also led to the development of haplotypes of two male controls (9948 and Taqmanan) used during the development of this multiplex assay for enabling other users for use as controls in their studies (Table 3 ).

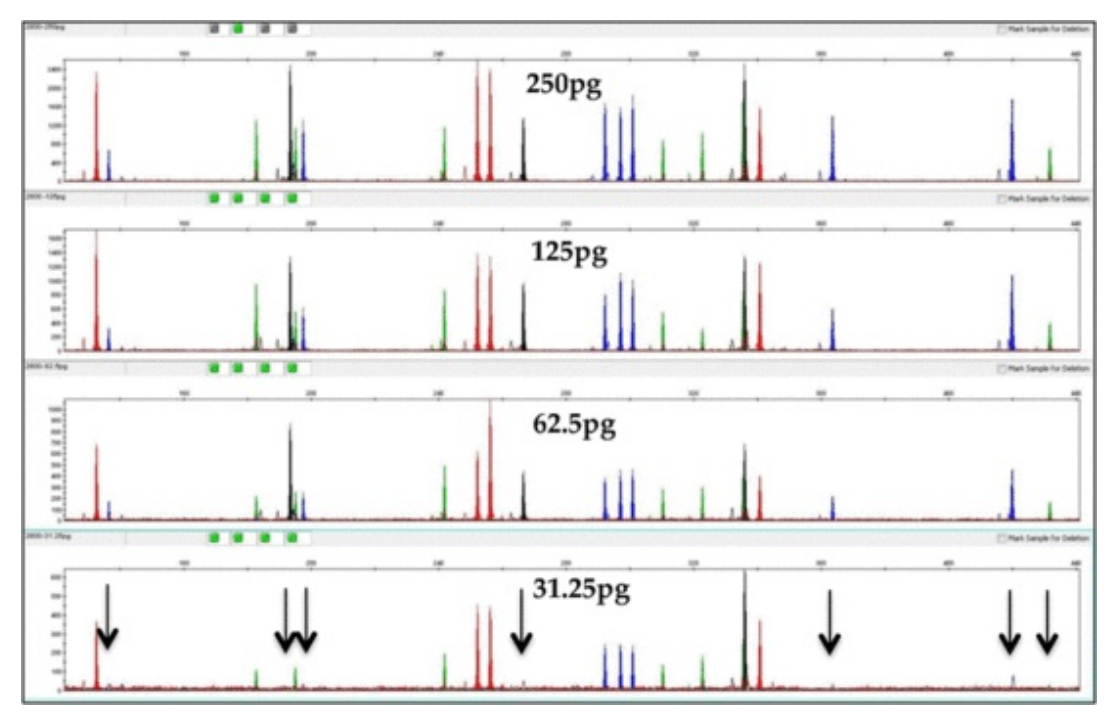

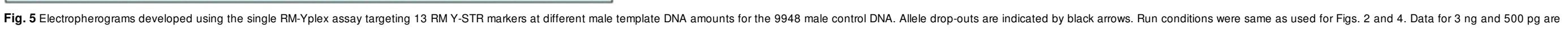
not shown in this figure. Note that panels are on different scales.

Table 3 RM-Yplex profiles for two commercial human male control DNAs. ${ }^{a}$ 


\section{elsevier_FSIGEN_1339}

\begin{tabular}{|c|c|c|}
\hline Locus & 9948 male control & TaqMan male control \\
\hline DYF387S1 & $35: 38$ & $36: 39$ \\
\hline DYF399S1 & 21:22:25.1 & $19: 23$ \\
\hline DYF403S1a & 10:15:16 & 11.2:12.2:15 \\
\hline DYF403S1b & 49 & 54 \\
\hline DYF404S1 & $12: 14$ & $15: 18$ \\
\hline DYS449 & 30 & 29 \\
\hline DYS518 & 38 & 42 \\
\hline DYS526a & 14 & 13 \\
\hline DYS526b & 36 & 34 \\
\hline DYS547 & 48 & 48 \\
\hline DYS570 & 18 & 19 \\
\hline DYS576 & 16 & 15 \\
\hline DYS612 & 37 & 36 \\
\hline DYS626 & 28 & 29 \\
\hline DYS627 & 22 & 21 \\
\hline
\end{tabular}

a Allele designation is according to the repeat nomenclature introduced by the International RM Y-STR Study Group [13].

\subsubsection{Mixture study}

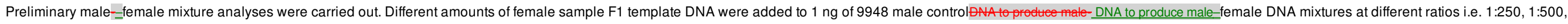

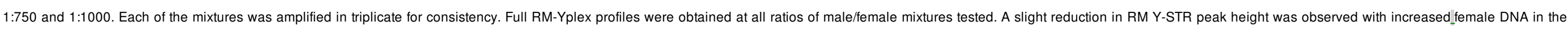
mixture(Figure (Fiq. 6). 


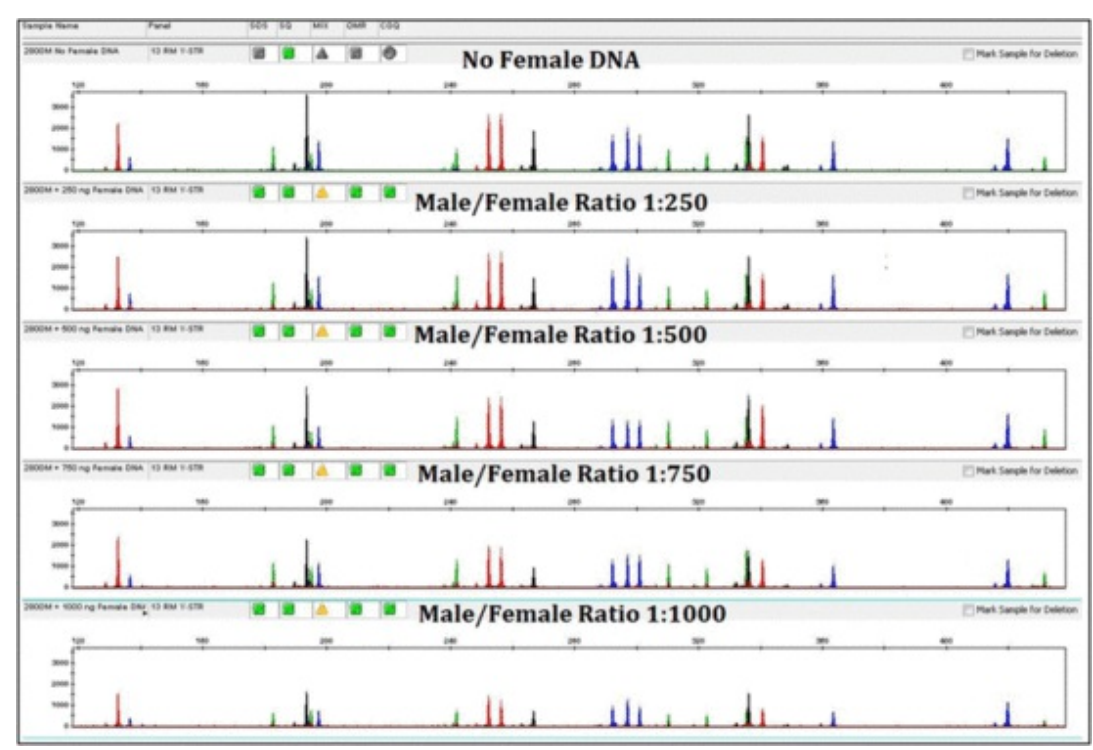

Fig. 6 Electropherograms from injecting RM-Yplex assay amplifications targeting 13 RM Y-STRs of mixturesconsisting of 1 ng male template DNA mixed with different amounts of female template DNA. Run conditions were same as used for Figs. 2 and 4.

\subsubsection{UAE family pedigree samples}

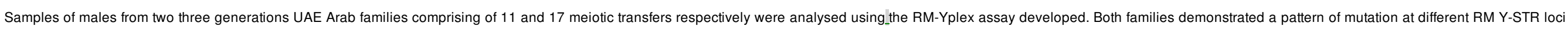

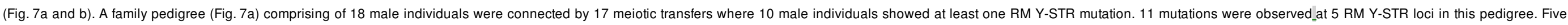

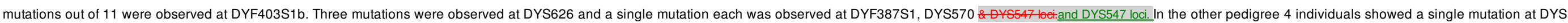

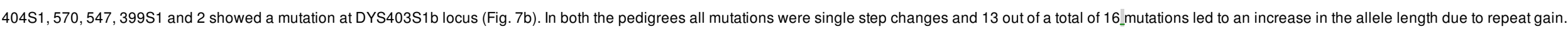

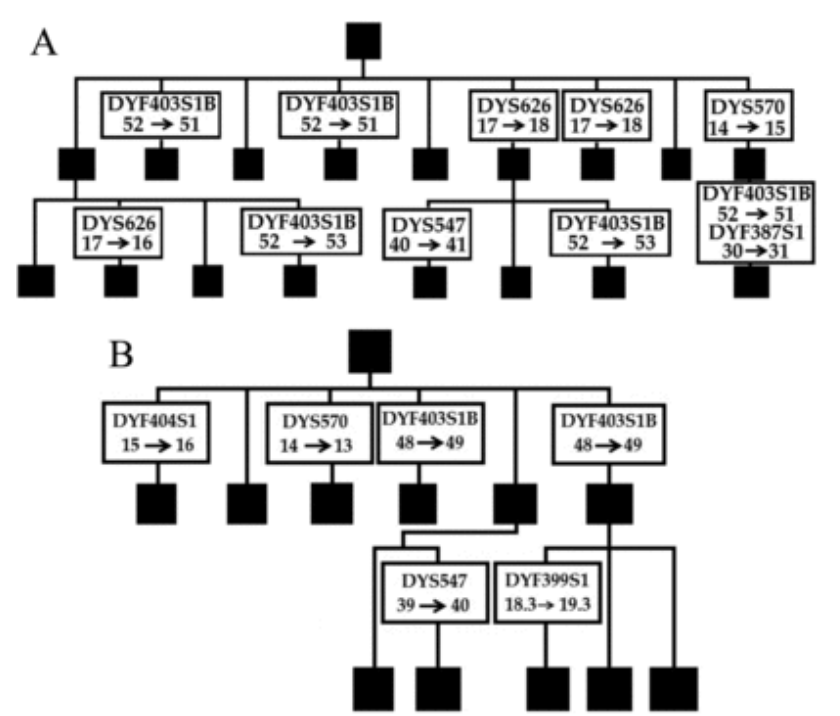

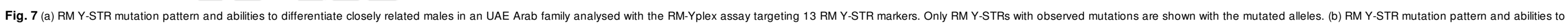
differentiate closely related males in an UAE Arab family analysed with the RM-Yplex assay targeting 13 RM Y-STR markers. Only RM Y-STRs with observed mutations are shown with the mutated alleles. 


\section{elsevier_FSIGEN_1339}

\section{Conclusions}

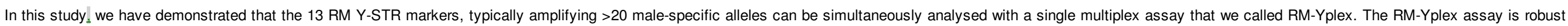

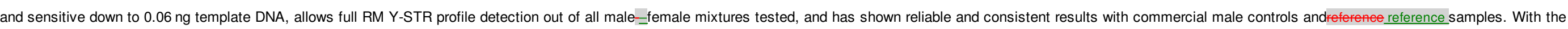

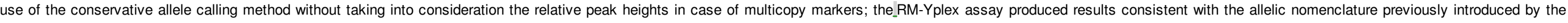

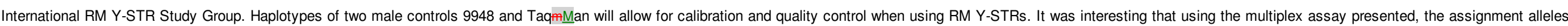

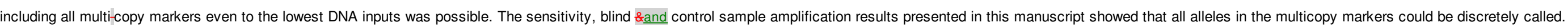

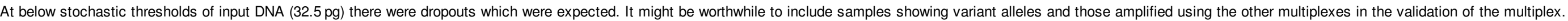
Due to the effective, robust, and sensitive way of analysing RM Y-STRs with our tool, we expect the RM-Yplex to become widely used for differentiating related and unrelated males in forensic and other applications.

\section{Acknowledgments}

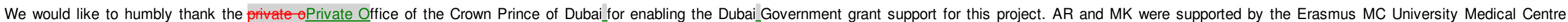
Rotterdam, The Netherlands.

\section{References}

[1]

M.A. Jobling and C. Tyler-_Smith, Fathers and sons: the Y chromosome and human evolution, Trends Genet. 11 (11), 1995, 449-456.

[2]

L. Roewer, Y chromosome STR typing in crime casework, Forensic Sci. Med. Pathol. 2, 2009, 77-84.

[3]

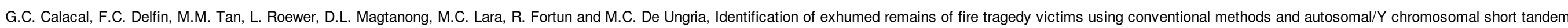
repeat DNA profiling, Am. J. Forensic Med. Pathol. 26 (3), 2005, 285-291.

[4]

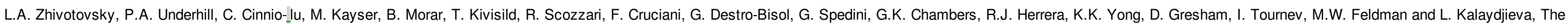
effective mutation rate at $Y$ chromosome short tandem repeats, with application to human population-divergence time, Am. J. Hum. Genet. 74 (1), $2004,50-61$.

[5]

J.M. Butler, R. Schoske, P.M. Vallone, M.C. Kline, A.J. Redd and M.F. Hammer, A novel multiplex for simultaneous amplification of 20 Y chromosome STR markers, Forensic Sci. Int. 129 (1), 2002, 10-24.

[6]

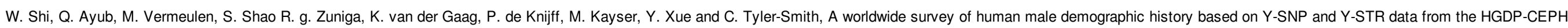
populations, Mol. Biol. Evol. 27 (2), 2010, 385-393.

[7]

W. Wei, Q. Ayub, Y. Xue and C. Tyler-Smith, A comparison of Y-chromosomal lineage dating using either resequencing or Y-SNP plus Y-STR genotyping, Forensic Sci. Int:. Genet. 7 (6), $2013,568-572$.

[8]

N. Leat, L. Ehrenreich, M. Benjeddou, K. Cloete and S. Davison, Properties of novel and widely studied Y-STR loci in three South African populations, Forensic Sci. Int. 168 (23), 2007, 154-161.

[9]

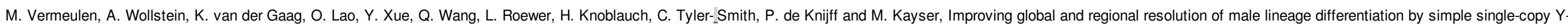




\section{elsevier_FSIGEN_1339}

chromosomal short tandem repeat polymorphisms, Forensic Sci. Int: Genet. 3 (4), 2009, 205-213.

[10]

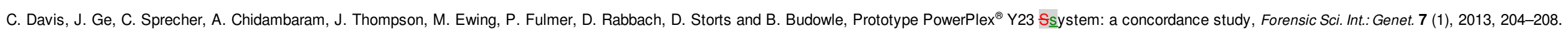

[11]

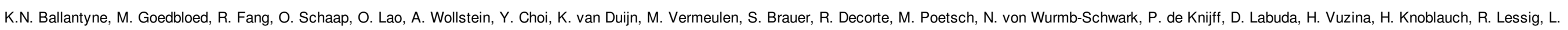

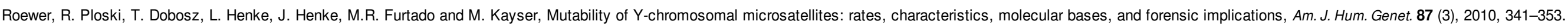

\section{[12]}

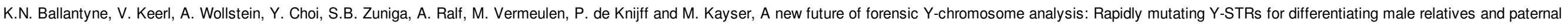
lineages, Forensic Sci. Int: Genet. 6 (2), 2012, 208-218.

[13]

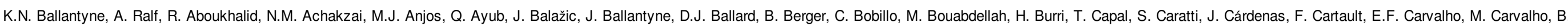

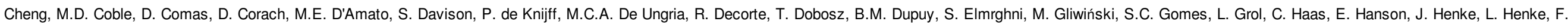

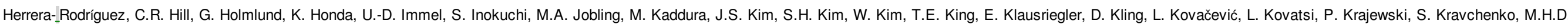

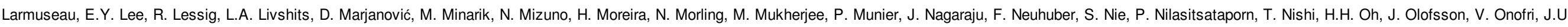

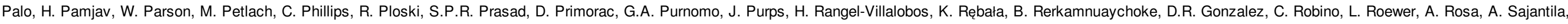
A. Sala, J.M. Salvador, P. Sanz, C. Schmitt, A.K. Sharma, D.A. Silva, K.-J. Shin, et al., Toward male individualization with rapidly mutating Y-chromosomal short tandem repeats, Hum. Mutat. 35, $2014,1021-1032$.

\section{[14]}

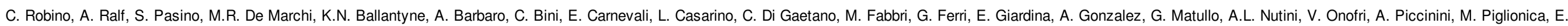

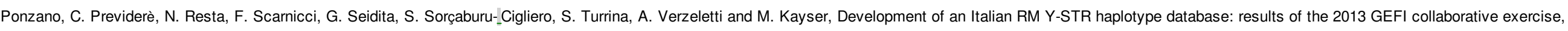
Forensic Sci. Int: Genet. 2013.

[15]

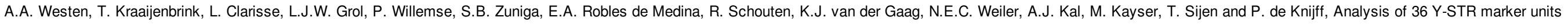
including a concordance study among 2085 Dutch males, Forensic Sci. Int.: Genet. 14, 2015, 174-181.

[16]

J.G. Shewale and R.H. Liu, Forensic DNA Analysis: Current Practices and Emerging Technologies, 2013, Taylor \& Francis.

\section{[17]}

A. Untergrasser, I. Cutcutache, T. Koressaar, J. Ye, B.C. Faircloth, M. Remm and S.G. Rozen, Primer3 - new capabilities and interfaces, Nucleic Acids Res. 15, $2012,115$.

\section{[18]}

T. Koressaar and M. Remm, Enhancements and modifications of primer design program Primer3, Bioinformatics 23 (10), 2007, 1289-1291.

\section{[19]}

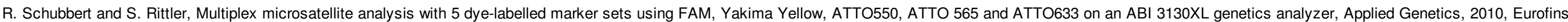
Medigenomix; Anzinger Str. 7a, 85560 Ebersberg. 


\section{elsevier_FSIGEN_1339}

Med. 111 (5), 1998, 267-272.

[21]

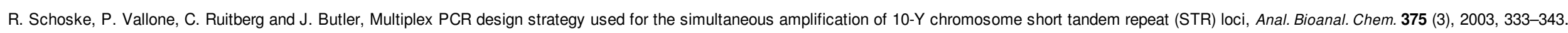

Highlights

- We present RM-Yplex amplifying 13 Papidly Arapidly mutating Y-STR markers.

- A sequenced allelic ladder developed for calling alleles of all loci is described.

- 8 PT samples with known RM haplotypes showed consistent results using RM-Yplex.

- Robust allele calls for all markers including multicopy markers up to 62.5 pg DNA

- Two Amale controls 9948 and TaqmMan haplotypes are presented for improving calibration.

\section{Queries and Answers}

Query: Please confirm that given names and surnames have been identified correctly.

Answer: Yes

Query: Please check the address for the corresponding author, and correct if necessary.

Answer: Yes

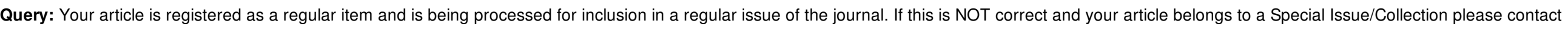
a.healey@elsevier.com immediately prior to returning your corrections.

Answer: It is a regular item.

Query: The unit "RFU" has been changed to "rfu" for consistency here and in subsequent occurrences. Please check, and correct if necessary.

Answer: That is fine with me

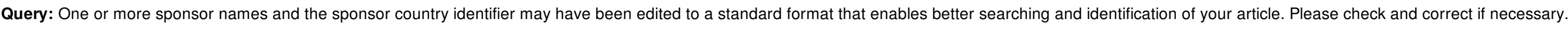

Answer: Yes 